\title{
o último Exílio de Jorge de Sena: Em Creta, com o Minotauro
}

\author{
Caio Gagliardi \\ Universidade de São Paulo
}

E me ne stacco sempre / straniero.

Giuseppe Ungaretti ${ }^{1}$

\begin{abstract}
m textos como o Timeu, o Livro X da República, e no seu último e inacabado diálogo, As leis, acompanhamos Platão realizando um cerceamento radical ao que chamamos, hoje, de "liberdade do escritor". A condenação da poesia decorre do desenvolvimento de um moralismo estético de matriz pitagórica, que encontra em Xenofonte uma síntese exemplar. Segundo o historiador e tratadista, para Sócrates todas as coisas que servem aos homens são ao mesmo tempo belas e boas na medida em que são de boa utilidade. De acordo com essa concepção original, a poesia interessava como propedêutica à filosofia, e não como valor absoluto. A concepção de satisfação desinteressada é completamente estranha ao pensamento socrático, em cujo âmbito a poesia se subordinava a outros valores, de ordem moral, para ter a sua existência justificada. Uma vez distante da ética estatal, portanto rebelde às intenções
\end{abstract}

${ }^{1}$ UNGARETTI, 2005. A estrofe completa: In nessuna / parte / di terra / mi posso / accasare / / A ogni / nuovo / clima / che incontro / mi trovo / languente / / che una volta / già gli ero stato assuefatto // E me ne stacco sempre / straniero. 
do legislador, a poesia fazia o papel de fonte transgressora, e como tal deveria ser excluída da cidade-estado ideal.

Esse é o lugar comum a partir do qual eu gostaria de pensar. A expulsão do poeta da República é bem conhecida e estudada. Aqui, apenas me valho dela pelo alto poder de sugestão e força metafórica que exerce sobre esta reflexão, uma vez que, deslocada de seu contexto matricial, e encarada da perspectiva do poeta, sua expulsão é antes uma redundância.

É essa redundância (oportunamente justificada) que me ajuda a enxergar uma das marcas mais singulares da poesia de Jorge de Sena.

Seria proveitoso um estudo que identificasse e analisasse as possíveis "respostas" que essa "expulsão" veio historicamente alimentando na literatura. Os seguintes fragmentos do ensaio "Erostratus", sobre a posteridade das obras de arte, de Fernando Pessoa, podem ser lidos nessa clave:

Em todos os casos, quanto mais nobre o gênio menos nobre o destino. Um gênio pequeno alcança a fama, um grande gênio alcança o descrédito, um gênio ainda maior alcança o desespero; um deus é crucificado.

(...)

Wilde nunca foi tão confirmadamente gênio como quando o homem na gare de caminho de ferro lhe escarrou na cara quando ele foi agrilhoado. Muitos gênios sofreram grave prejuízo: ainda ninguém lhes escarrou no rosto. ${ }^{2}$

Desse ângulo específico, a pena de expulsão da cidadeestado ideal pode ser lida como um prêmio.

Não é, esteja claro, o caso de reduzir a gravidade desse banimento. Para o homem do mundo pré-moderno, sem poder contar com um sistema eficiente de comunicação e preso à sua classe social, ser desterrado era uma punição muito severa, em

${ }^{2}$ PESSOA, 1973, p. 163-276. 
muitos casos equivalente à sentença de morte. O exilado não era o refugiado, tal como entendemos hoje, mas o degredado. Ser banido de sua terra implicava, geralmente, um distanciamento sem volta e a imersão num estado de mendicância. Considerado pior do que a pena capital, o "exilium", ou "exílio romano", levava basicamente à animalização do indivíduo, que era proibido de cozinhar seus alimentos, entrar em qualquer habitação e mesmo se dirigir a outro indivíduo. As biografias de Ovídio (exilado em Roma e Tomis, por Augusto, que se sente moralmente ofendido pela Ars Amatoria, então tomada como um manual para amantes inexperientes), Dante (banido de Florença, por motivos políticos) e Camões (poeta de um triplo exílio, na Índia, China e Macau, decorrentes de uma briga de rua) são exemplos contundentes de como a deportação atua decisivamente sobre a escrita.

No entanto, mesmo para esses poetas, a quem o exílio resultou numa experiência hostil e torturante, ela pode ser ampliada para além do trauma particular: é comum encontrar entre seus leitores afirmações que relacionam de modo determinante a experiência do exílio à escrita de suas obras. Em outras palavras, o sentimento de desenraizamento, que é fruto do exílio, conforma uma espécie de estado de emancipação, do qual também a ética estatal, advogada por Platão, foi banida, e no qual se abre um espaço de liberdade propício à escrita.

"E me destaco sempre / estrangeiro." A última estrofe do poema de Ungaretti, aqui citada como epígrafe, define tanto um destino humano quanto uma poética.

Como exilado, o poeta parte de um local, a sua pátria (exceto, é claro, aquele que escreve hinos à mesma, que é poupado por Platão), para se estabelecer num outro espaço. Dirse-á que, por exemplo, um Bernardo Soares não sai de Lisboa que é ali que escreve todo o seu diário íntimo. Mas éjustamente essa sua condição particular que é reveladora de que o exílio 
não é um mero afastamento geográfico: a natureza psicológica de seu afastamento torna-o mais decisivo. Apenas enquanto exilado o poeta pode se perfazer. O exílio, tomado como forma radical de deslocamento, incorpora-se à atitude poética.

Talvez comece a ficar clara, aqui, a minha leitura da expulsão do poeta da República como uma redundância. É que, enquanto poeta, o seu espaço-ideal já não é a República, e a sua poesia é uma forma de resistência a ela.

Buscar o respeito dos outros é o contrário de qualquer projeto literário, porque te leva à imobilidade, ao consenso, aos votos e a uma posição na sociedade. E o escritor não deve buscar uma posição na sociedade. Pelo contrário, deve fugir dela. Seu lugar é o ar livre e sua casa é a intempérie. ${ }^{3}$

O lugar da poesia de Jorge de Sena é a intempérie.

Esse é o prólogo de minha aproximação, uma vez que Jorge de Sena vivenciou um duplo exílio. Mas eu diria, desde já, que encarnou com especial intensidade o pathos do exilado, convertendo-o num ethos, isto é, em substância decisiva de sua poética. Um assujeitamento que é, digamos, convertido em abrigo.

Urbano Tavares Rodrigues notou que toda a poesia de Camilo Pessanha é poesia de exílio. Tanto em Macau como em Lisboa, e mesmo nas terras de sua infância, o crítico identifica no exílio o tecido da existência do poeta. ${ }^{4}$ Embora em Jorge de Sena o sentimento do exílio não evolua para nostalgia ou langor, tal como Paulo Franchetti revelou se suceder na poesia

${ }^{3}$ BOLAÑO, set. de 2010.

${ }^{4}$ RODRIGUES, 1970. 
de Pessanha, ${ }^{5}$ parece-me que o mesmo se pode dizer a seu respeito, para quem a condição individual de exilado se torna, para além de uma simples experiência de perda ou subtração, uma condição de existência; isto é, exilado não apenas no Brasil e nos Estados Unidos, mas também em Portugal. O espaço, não apenas destinado, mas tenazmente procurado pelo poeta Jorge de Sena é o dos deslegitimizados. ${ }^{6}$

O exílio não se limita a motivar a escrita, como também se institui a partir dela.

É Jorge, alter ego do autor e protagonista de seu romance de formação, deixado inacabado, Sinais de fogo, quem afirma: "Poeta, pra mim, como para minha família, e para meus amigos, era uma pessoa algo caricata, segregada da normalidade da vida." 7

A terra de origem e o chão do exílio revestem-se, na verdade, do mesmo sentimento de deslocamento, de desconcerto com o meio, que se revela determinante para a escrita. É como divergência desintegradora que a poesia de Jorge de Sena arranha o espírito unificador nacionalista, denunciando, indiretamente, sua crise de autoconsciência.

As pressões da sobrevivência estão fortemente vinculadas à experiência do afastamento do solo natal em Jorge de Sena. E sua poesia, alimentada pelo espírito neo-realista dos anos 40, é em larga medida uma lírica testemunhal da experiência do duplo exílio do autor, no Brasil e posteriormente nos Estados Unidos.

${ }^{5}$ FRANCHETTI, 2001.

${ }^{6}$ Em Portugal, com especial relevo, a experiência do exílio é uma constante histórica. A mística construída em torno da saudade como tópica cultural e literária apóia-se numa base histórica bastante sólida. A poesia de Jorge de Sena é mais um dos exemplos contundentes dessa constante.

${ }^{7}$ SENA, 1979, p. 484. 
Lembremos que o então engenheiro civil Jorge de Sena, escritor pouco reconhecido e construtor de estradas, participa ativamente de uma conjura anti-salazarista em 1959, o chamado Golpe da Sé. O Estado dá início às perseguições políticas, levando muitos de seus participantes a julgamento. Relacionado a esse episódio está o assassinato do capitão Almeida Santos, um dos cabeças do movimento, que é preso e, durante a fuga, acaba sendo assassinado (segundo a versão oficial, pelos outros dois companheiros, por razões passionais), aparecendo o seu cadáver numa praia. Este episódio tornou-se fonte referencial para o romance de José Cardoso Pires, A Balada da Praia dos Cães, de 1982. O romance é o relato da investigação do assassinato e, ao mesmo tempo, um corrosivo retrato do Estado Novo.

À época da conjura de 59, Sena tem nada menos que sete filhos, e portanto motivos de sobra para recear uma perseguição. O convite para participar de um congresso na Bahia (o $4^{\circ}$. Colóquio Internacional de Estudos Luso-Brasileiros, organizado por dois dos mais eminentes críticos portugueses, Adolfo Casais Monteiro - a essa época residente no Brasil - e Eduardo Lourenço) é a oportunidade para mudar-se para cá e tornar-se professor universitário. O cenário brasileiro é, a essa altura, promissor. Vivemos os últimos anos da Era JK (56-61), os chamados Anos Dourados, um momento em que o clima era de confiança e de esperança no futuro. Com o Plano de Metas e a rápida industrialização da economia, o país se urbaniza e adota o "american way of life", mantendo a democratização social. Decerto que não era um Eldorado, mas um país muito distante daquele do outro lado do Atlântico, em que Sena, depois de adulto, jamais experimentara a liberdade política. $\mathrm{O}$ autor se doutora em Letras, em Araraquara, e passa a lecionar em Assis, naturaliza-se brasileiro, obtém o diploma de LivreDocência e colabora assiduamente com o jornal Portugal Democrático. Segundo Gilda Santos, Sena vive aqui seu período intelectualmente mais criativo: 
Os seis anos brasileiros da vida de Jorge de Sena - além de solidificarem no mais alto nível seus percursos de poeta, de ficcionista, de crítico literário, de conferencista, de articulista em periódicos capaz de versar sobre os mais variados temas culturais -, vêm revelar o docente, o pesquisador scholar, o organizador de eventos e de publicações, o militante anti-salazarista que afinal pode falar claramente de suas convicções. ${ }^{8}$

No ano seguinte ao golpe militar de 1964, surge, oportunamente, a possibilidade de mudar-se para os Estados Unidos, com Mécia de Sena e os seus, agora, nove filhos. Nos EUA, de onde não mais se mudará (a não ser para viagens esporádicas), é nomeado professor catedrático em Wisconsin, Madison, e depois na University of California, em Santa Barbara (UCSB).

Essa rica trajetória contribuiu para fazer de Jorge de Sena o intelectual português mais cosmopolita e internacionalmente reconhecido de sua geração. Referindo-se ao falecimento do escritor, em 1978, Eugénio Lisboa afirmou ter morrido "um dos raros portugueses universais de nosso tempo". Essa universalidade se deveu, no entanto, e justamente, ao que Carlos Drummond de Andrade apontou como uma falta: "Faltou a Jorge de Sena uma pátria constante e receptiva, que agasalhasse o seu destino de intelectual e erudito a serviço exclusivo do espírito." 9

No entanto, se considerarmos bem, essa "falta", que Drummond parece circunstanciar não apenas biograficamente, converte-se justamente em uma de suas experiências poéticas mais pujantes.

Eu gostaria de me valer de um outro empréstimo para recusar a noção de "falta" apontada por Drummond. No fim de seu ensaio "Filologia da Literatura Mundial", Auerbach cita uma

${ }^{8}$ SANTOS, 2001, p. 62.

${ }^{9}$ ANDRADE, 1984, p.112. 
frase de Ugo di S. Vittore, teólogo agostiniano do século XVII, que toma abertamente, não no seu sentido metafísico original, de "libertação do amor às coisas terrenas", explica Auerbach, mas como declaração de "amor ao mundo". Declaração esta que, acrescentamos, desembaraça-se da trama "nacional":

O grande princípio da virtude é que o espírito, exercitado paulatinamente, aprenda primeiro a transformar estas coisas visíveis e transitórias, para que em seguida possa mesmo abandoná-las. Delicado é aquele para quem a pátria é doce. Bravo, aquele para quem a pátria é tudo. Mas perfeito é aquele para quem o mundo inteiro é exílio... ${ }^{10}$

O exílio e a errância, convertidos em experiências poéticas pujantes, e arvorados por um intelectualismo discordante, balizam, na poesia de Jorge de Sena, uma perspectiva crítica e cosmopolita a respeito das crenças e valores nacionais.

Do ensaio de Auerbach colhemos a expressão weltliteratur, "literatura mundial", que nos parece bastante apropriada como baliza para o ideal estético seniano. Weltliteratur é um conceito qualitativo, na medida em que contrapõe o universal ao nacional. Jorge de Sena é herdeiro do repúdio goetheano ao patriotismo, inerente às suas reflexões sobre a weltliteratur:

Com pátrias nos compram e nos vendem, à falta de pátrias que se vendam suficientemente caras para haver vergonha de não pertencer a elas. Nem eu, nem o Minotauro, teremos pátria nenhuma.

${ }^{10}$ Apud AUERBACH, 2007, p. 373. O texto latino original é o seguinte: Magnum virtutis principium est, ut discat paulatim exercitatus animus visibilia haec et transitoria primum commutare, ut postmodum possit etiam dereliquere. Delicatus ille est adhuc cui patria dulcis est, fortis autem cui omne solum patria est, perfectus cui mundus totus exilium est... 
"Em Creta, com o Minotauro", 11 poema matizado por um espírito cosmopolita que supera os regionalismos culturais, nos deparamos com um eu lírico exilado e que não reconhece fronteiras ou raízes nacionais:

Nascido em Portugal, de pais portugueses, e pai de brasileiros no Brasil, serei talvez norte-americano quando lá estiver.

Colecionarei nacionalidades como camisas se despem, se usam e se deitam fora, com todo o respeito necessário à roupa que se veste e que prestou serviço.

A nação está a serviço do poeta, e não o contrário. E ele a usa e a dispensa quando julgar que ela não mais lhe serve. Não é, portanto, a pátria que constrói sua identidade. A identidade é uma escolha individual, aqui pautada num intelectualismo sem fronteiras, que se contrapõe ao patriotismo cristalizado pelo hábito.

Nesse canto de libertação ao nacional, aparentado aos de outros poetas auto-exilados em deambulação - como Murilo Mendes, na Itália, ou Giuseppe Ungaretti, no Brasil -, o refúgio é Creta, dimensionada como um protolugar, um espaço anterior às nações. Em Creta, Sena encontra outro exilado, o Minotauro, que ao invés de devorá-lo, tomará café consigo. Creta é um lugar literário cuja força arquetípica é similar à Pasárgada - não à de Ciro, rei dos Persas, mas à de Manuel Bandeira -, lugar de evasão da vida besta e cotidiana. A exemplo de Thomas More, Manuel Bandeira e Jorge de Sena produziram suas utopias. Embora tenham sido fundadas há milhares de anos, Pasárgada e Creta adquirem, nos poemas que as trazem nos títulos, o papel de lugares utópicos, isto é, idealizados e contrários ao mundo real.

Pode-se dizer, portanto, que esse eu lírico, bastante aderente ao sujeito biográfico Jorge de Sena, vai-se embora

${ }^{11}$ SENA, 1978. 
para Creta, que já não é mais a do rei Minos - e sim lugar de evasão da vida nacional. Por analogia, se Pasárgada é o mundo em que Bandeira não é tísico, Creta é aquele em que Sena não é português. A libertação das fronteiras do espaço e do próprio corpo, em ambos os poemas, estende-se, no entanto, em Sena, à libertação cultural e lingüística. Desprende-se da poesia uma espécie de voz estrangeira, reagente ao espírito conciliatório nacionalista:

Conversaremos em volapuque, já que nenhum de nós o sabe. O Minotauro não falava grego, não era grego, viveu antes da Grécia, de toda esta merda douta que nos cobre há séculos, cagada pelos nossos escravos, ou por nós quando somos os escravos de outros. Ao café, diremos um ao outro as nossas mágoas. ${ }^{12}$

Nem o português, nem o grego. No seu lugar, uma língua artificial (e que ninguém sabe) criada em 1880 por um padre católico alemão, o volapuque (vol - mundo; puk - língua). Por que o volapuque?

Essa pergunta nos encaminha ao ponto de chegada deste ensaio. Cabe considerar que o adágio pessoano, latente no referido poema, "A minha pátria é a língua portuguesa" (Bernardo Soares), foi objeto de uma apropriação ideológica descontextualizadora (por um misreading radical - porque, se considerado no contexto de todo o fragmento 259 do Livro do Desassossego, apresenta conotações repressivas e imperiais). A banalização da frase transformou-a em baliza da noção, atualmente em voga, de lusofonia. Tendo perdido o império, seria interessante ao português que a idéia de Portugal não mais se confiasse à territorialidade que lhe resta. A lusofonia

${ }^{12}$ SENA, 1978. 
foi, no fundo, a resposta portuguesa à perda do império, oferecendo-lhe contornos pós-imperialistas, na medida em que não discrimina mais cidadãos de não-cidadãos, ou seja, que não hierarquiza os indivíduos a partir de sua etnia ou classe social. É ainda, e a meu ver, um projeto imperial, embora já sem encarnar o "fardo do homem branco".

Ora, definir-se por uma cultura e uma língua, tal como preconiza a noção de lusofonia, é para Jorge de Sena uma rendição. Sua atitude é, afinal, francamente desterritorializante. A seu ver, não restaram pátrias de que se orgulhar: todo lugar é loca infecta (daí o título do livro, que não é outra coisa senão um diário do poeta errante pelo mundo, Peregrinatio ad loca infecta). A língua (e também a cultura), reduzida a uma herança casual, e tratada como convenção, longe de ser uma pátria, não mais representa verdade alguma: "A pátria / de que escrevo é a língua em que por acaso de gerações / nasci."

"Somente a pouquíssimos homens", afirma Adorno na "Palestra sobre Lírica e Sociedade", "devido às pressões da sobrevivência, foi dado apreender o universal no mergulho em si mesmos" ${ }^{13}$ Através da aparente contradição de um de seus versos centrais, "O Minotauro compreender-me-á", o poema de Jorge de Sena revela uma posição do eu lírico face não apenas à sua pátria como à humanidade como um todo. Assim como o Minotauro, Sena experimenta o alijamento. Poeta do riso demoníaco, avivador de consciências contra a falta de humanidade entre os ditos civilizados, Sena enxerga o Minotauro como representação, não apenas parcial, mas integral do gênero humano: "É metade boi e metade homem, como todos os homens". Na Ars Amatoria de Ovídio, aliás outro exilado, encontramos o verso precursor deste outro, "Semibovemque virum semivirumque bovem" . Já no poema

${ }^{13}$ ADORNO, 2003, p. 76. 
de Sena, assim como o Minotauro é humanizado por seu olhar transformador, a bestialidade deixa de ser compreendida como o contrário, para ser parte definidora do ser humano.

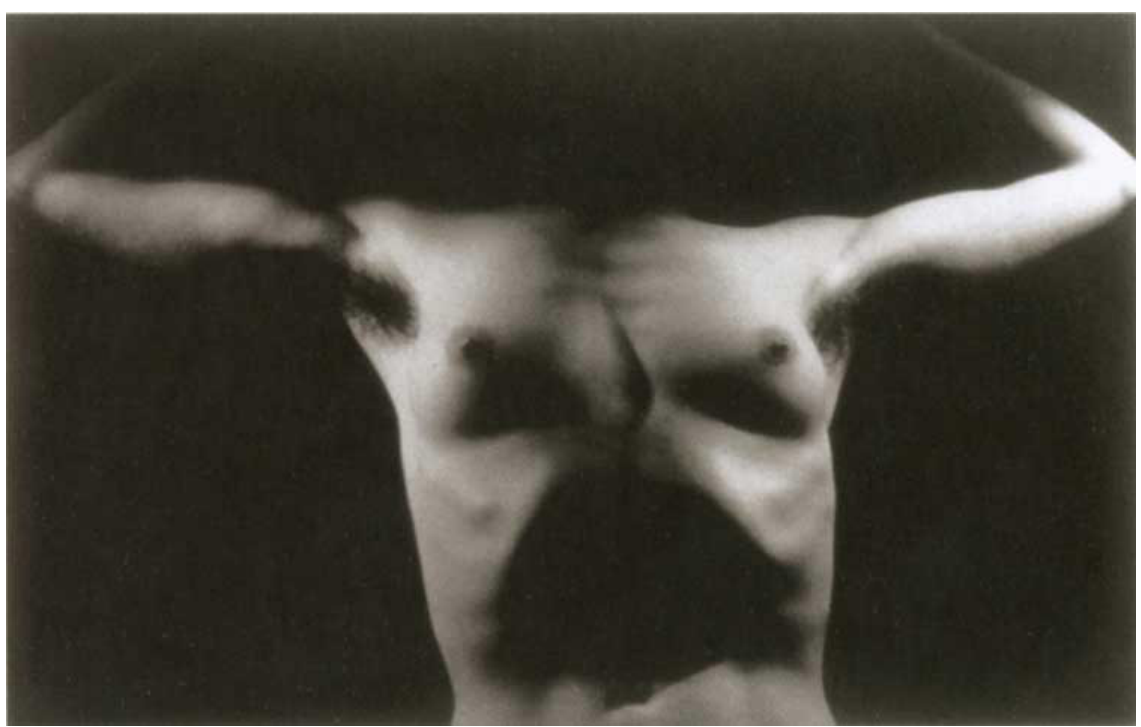

http://www.creativepooldesign.de/mood_art/artimages/traces_du_sacre/ traces_du_sacre-58.jpg

Expulso da República portuguesa, "sem pátrias e sem espírito", limpo de toda a carga cultural e de toda a civilização, "sem nada nem ninguém, / que não o dedo sujo", mas "Em Creta, com o Minotauro", Jorge de Sena tomou em paz o seu café. 


\section{Referências bibliográficas}

ACHCAR, Francisco. "Platão contra a poesia". Revista USP: 151-158. Dez-Fev., 1991.

ADORNO, Theodor. "Palestra sobre lírica e sociedade". Notas de Literatura I. Trad. Jorge de Almeida. São Paulo: Duas Cidades/Editora 34, 2003.

AUERBACH, Erich. "Filologia da Literatura Mundial". In: Ensaios de literatura ocidental - filologia e crítica. Org. de S. Titan Jr. e D. Arrigucci Jr. São Paulo: Duas Cidades / Ed. 34, 2007.

BOLAÑO, Roberto. Entrevista (Arquivo Bolaño). In: http:/ / garciamadero.blogspot.com/

FRANCHETTI, Paulo. Nostalgia, Exílio e Melancolia - leituras de Camilo Pessanha. São Paulo: Edusp, 2001.

LISBOA, Eugênio (org.). Estudos sobre Jorge de Sena. Lisboa: INCM, 1984. PLATÃO. A República. Trad. M. H. R. Pereira. Lisboa: Fundação Calouste Gulbenkian, 1993.

PESSOA, Fernando. "Erostratus - ensaio sobre a fama póstuma de obras literárias". In: Páginas de estética e de teoria e de crítica literárias. Org. Georg Rudolf Lind e Jacinto do Prado Coelho. Lisboa: Ática, 1973. RODRIGUES, Urbano Tavares. "Aproximação da poesia de Camilo Pessanha”. In: Ensaios de escreviver. Porto: Editorial Inova, 1970.

SANTOS, Gilda. "Da arte de ser multiplamente português". In: Jorge de Sena vinte anos depois. O colóquio de Lisboa - Outubro de 1998. Lisboa: Câmara Municipal de Lisboa / Edições Cosmos, 2001.

SENA, Jorge de. "Em Creta, com o Minotauro". Peregrinatio ad loca infecta. In: Jorge de Sena - Poesia III. Lisboa: Moraes, 1978.

Sinais de Fogo. Lisboa: Edições 70, 1979.

UNGARETTI, Giuseppe. “Girovago” (1918). In: Vita d'un uomo. Tutte le poesie (L'Alegria, 1931). Milano: Mondadori, 2005.

XENOFONTE. Memoráveis. Trad. do grego, introd. e notas de Ana Elias Pinheiro. Coimbra: CECH, 2009. 


\section{Resumo}

A experiência de deslocamento de um dos principais escritores portugueses do século XX, Jorge de Sena, é ao mesmo tempo uma experiência biográfica e literária. Seu duplo exílio no Brasil e nos Estados Unidos é incorporado por sua escrita a ponto de elevar o exílio a um estado poético. A emancipação das fronteiras nacionais, a errância e o sentimento de alienação levam o poeta a sonhar com um exílio perfeito, um último exílio ou um estado de escrita permanente: em Creta, tomando café com o Minotauro. O Minotauro é seu verdadeiro duplo na mitologia. Essa transição para o universo do insólito significa uma abertura muito expressiva de sua poesia para mundos desconhecidos, e é inseparável da experiência de expatriação vivida por Jorge de Sena.

\section{RÉSUMÉ}

L'expérience du déplacement d'un des principaux écrivains portugais du XXe siècle, Jorge de Sena, constitue à la fois une expérience biographique et littéraire. Son double exil au Brésil et aux Etats-Unis est incorporé par son écriture au point d'élever l'exil à un état poétique. L'émancipation des frontières nationales, l'errance et le sentiment de déracinement conduisent le poète à rêver d'un exil parfait, un dernier exil ou un état de permanent écrit: en Crète, en sirotant un café, avec le Minotaure. Le Minotaure est son véritable double dans la mythologie. Ce passage à l'univers de l'insolite signifie une très importante ouverture de sa poésie vers des mondes inconnus, et c'est indissociable de l'expérience du dépaysement vécue par Jorge de Sena. 